\title{
THE DEVELOPING HUMAN FOETUS- RELATIVE GROWTH OF UTERUS COMPARED TO OVARIES
}

\author{
Keisam Anupama Devi' ${ }^{1}$ Renuca Karam²
}

${ }_{1}^{1}$ Assistant Professor, Department of Anatomy, Jawaharlal Nehru Institute of Medical Sciences, Porompat, Imphal, Manipur, India. ${ }^{2}$ Assistant Professor, Department of Anatomy, Jawaharlal Nehru Institute of Medical Sciences, Porompat, Imphal, Manipur, India.

\section{BACKGROUND}

ABSTRACT

Uterus is a constituent of the internal female reproductive tract which develops from a paired paramesonephric duct, originating from coelomic epithelium extending beside the mesonephric ducts. The paired duct begins to fuse from vaginal plate and forms the primordial body of the uterus and the unfused lateral arms form the uterine tubes.

Data regarding the development and maturation (ontogeny) of the uterus in human foetuses of different age groups is scarce, necessitating further study of the most important female genital organ.

\section{MATERIALS AND METHODS}

Seventy (70) foetuses of different Crown-Rump Lengths (CRL) and ranging from $14^{\text {th }}$ week to $40^{\text {th }}$ weeks were studied in the Department of Anatomy, Regional Institute of Medical Sciences (RIMS), Imphal, Manipur. The developmental stages of the uterus and ovaries from 14 weeks onwards till term were studied, categorised into six groups of specific age period. Time of appearance to naked eye and its gross study, gradual maturation and corresponding changes in size and shape of the uterus and ovaries as age advances and dimensions were recorded.

\section{RESULTS}

The foetal uterus was located in the false pelvis between the urinary bladder anteriorly and rectum posteriorly. Cervical segment is more than the uterine body throughout foetal life. The ratio of the length of the uterus to the ovary expressed in decimal form is 0.73 from 14 - 18 weeks. By 20 weeks, the ratio becomes 1.0. Thereafter, 24 weeks onwards the uterus overgrows the ovaries progressively and the ratio of the lengths reverses and attains a ratio of 1.79 at 40 weeks.

\section{CONCLUSION}

In the earliest specimen i.e. $14^{\text {th }}$ week gestational age, ovary measures $9.5 \mathrm{~mm}$ and uterus measures $6.93 \mathrm{~mm}$, ratio being 0.73 . By the 18th week, the dimension is similar at $10 \mathrm{~mm}$ each and the ratio reaches 1.0. Thereafter, the ovaries continue to outgrow the uterus and by the $26^{\text {th }}$ week the ovary-uterine ratio reaches 1.46 . This reversal of ratio remains mainly steady till term size. The developing uterus was in close relation with the ovaries and remains so till $36^{\text {th }}$ week of gestation.

\section{KEY WORDS}

Foetus, Mesonephric Duct, Ovary, Paramesonephric Duct, Uterus.

HOW TO CITE THIS ARTICLE: Devi KA, Karam R. The developing human foetus- relative growth of uterus compared to ovaries. J. Evolution Med. Dent. Sci. 2018;7(44):4781-4784, DOI: 10.14260/jemds/2018/1066

\section{BACKGROUND}

The uterus is the most important reproductive organ present in the pelvis, a constituent of the internal female reproductive tract which develops from a paired paramesonephric duct, originating from coelomic epithelium extending beside the mesonephric ducts. The paired duct begins to fuse from vaginal plate and forms the primordial body of the uterus and the unfused lateral arms form the uterine tubes. 1,2,3,4,5

The paired paramesonephric duct goes through a series of developmental changes regulated by a number of molecular factors through initiation, invagination to the coelomic cavity and elongation of the ducts forming the uterine horns, begins fimbrial development and continues after birth. The tubes can be traced on either side to a round object regarded as the ovary. ${ }^{6}$

'Financial or Other Competing Interest': None.

Submission 30-09-2018, Peer Review 13-10-2018,

Acceptance 16-10-2018, Published 29-10-2018.

Corresponding Author:

Dr. Renuca Karam,

Department of Anatomy,

Jawaharlal Nehru Institute of Medical Sciences,

Porompat, Imphal, Manipur, India.

E-mail: krenuca@gmail.com

DOI: $10.14260 /$ jemds $/ 2018 / 1066$
The majority of medieval gynaecological writers described the uterus as having seven chambers except Galen who described the uterus as bi-lobed following the anatomy of monkey which he was accustomed to dissecting. He called the cavity of uterus "via uteri" and detailed the expanded and narrowed neck of cervix and its passage to the vagina. ${ }^{6}$

For more than 100 years, the development of uterus in humans and other mammals have been studied and the Mullerian duct is well known as the anlage of the uterus. Different interpretations of the developmental mechanism of Mullerian duct has been proposed and Felix concept in 1912 as an independent outgrowth from the ostium changed to Grunwald theory that the Mullerian duct splits off from the Wolffian duct. ${ }^{7}$ Potemkina $\mathrm{DA}^{8}$ recognised the development of the Mullerian duct that depends on the presence of the Wolffian duct after noticing a simultaneous thickening of the side of the Wolffian duct before the ostial rudiment of the Mullerian duct appeared.8,9,10,11 The systematic development of the Mullerian duct and uterus in humans became clearer in the last few decades after pioneering works explaining the embryology ranging in age from $44-56$ days. ${ }^{7}$ Data obtained through dissections of human foetuses in this regard helps in identifying uterine developmental variations, anomalies and pathologies thus contributing to obstetrics, perinatology, forensic medicine and foetal pathology departments. 


\section{MATERIALS AND METHODS}

The cross-sectional study was carried out on the uteri of 70 (Seventy) lifeless fresh human foetuses of different gestational ages ranging from 14 weeks (CRL-10 cm) to 40 weeks (CRL-38 cm) collected from the Department of Obstetrics and Gynaecology, RIMS, Imphal, which were the products of terminated pregnancy under the Medical Termination of Pregnancy Act of India, 1971 and stillbirths due to spontaneous miscarriage or intrauterine death for a period of two years from September 2011 to September 2013. Foetuses which did not have any external pathology or anomaly comprised the study group. Written informed consent of the parents and permission from the Medical Superintendent, RIMS, Imphal were obtained. The specimens were utilised for the present study after seeking permission and receiving approval from the Institutional Ethical Committee.

The age of the foetuses were calculated from the obstetrical history (First day of the last maternal menstruation), gross features and crown-rump lengths. The foetuses were preserved in $10 \%$ formalin for 10 to 15 days. Only those foetuses which were free from any gross anatomical abnormality were selected. The specimens were categorised into different age groups for easier study and observation, as there will be similar features and finding in the adjacent age consisting of Group I: 14 to 18 weeks, Group II: 18 to 22 weeks, Group III: 22 to 26 weeks, Group IV: 26 to 30 weeks, Group V: 30 to 34 weeks and Group VI: 34 to 40 weeks.

After proper preservation, the weight of the foetuses was recorded (in grams) before dissection was commenced. The abdominal parts of the foetus were dissected by making vertical infraumbilicaI midline or paramedian incision and the uterus along with ovaries were identified and accessed. The relationship and dimensional measurements of the paired ovaries were recorded for comparative studies. Thereafter, the uteri were carefully isolated out from the surrounding structures and excised. The excised uterus was studied in detail for gross features. Measurements were taken for the antero-posterior, longitudinal and transverse dimensions of the corpus and cervix and ovaries. The transverse length of the corpus was measured at the level of the uterine tubes. The data were entered in Microsoft Excel. Descriptive statistics like proportions, mean and Standard Deviation (SD) were used. A Pearson correlation coefficient was computed to assess the relationship between the increases in uterine length to that of ovarian length.

\section{RESULTS}

The developmental stages of the uterus and ovaries from $14^{\text {th }}$ week onwards till term were categorised into six specific age groups: Group I comprising 14 - 18 weeks, Group II comprising 18 - 22 weeks, Group III comprising 22 - 26 weeks, Group IV comprising 26 - 30 weeks, Group V comprising 30 - 34 weeks and Group VI comprising 34 - 40 weeks of gestation. Growth and development at different age period were studied.

\section{Group I (14 - 18 Weeks)}

In the earliest specimen, the primordium of the uterus is identifiable to the naked eye as a whitish mesodermal thickening in the midline in the false pelvis concealed by coils of intestine. After retraction of coils of intestine, it is seen present between the urinary bladder in front and rectum behind separated by vesicouterine pouch and rectouterine pouch respectively. The two ovaries present posterior to the uterine tubes measures $9 \mathrm{~mm}$. The ratio of the length of the uterus to the ovary is 0.73. Both ovaries are disproportionately much extensive and larger than the uterus. The medial ends of the two ovaries lies close to each other, which is present posterior to the corpus of the uterus. The ovaries on the posterior surface is also covered by a jellylike membrane, the primitive peritoneum and continuous with layer of broad ligament. At $18^{\text {th }}$ week, the developing uterus gradually changed its shape and becomes firmer with increase in size. The uterine tubes are longer and tortuous and the length of the ovary becomes similar to the uterus, each measuring $8 \mathrm{~mm}$.

\section{Group II (18 - 22 Weeks)}

The pelvis becomes roomy than the previous age group filled with developing ovaries, rectum and urinary bladder. The developing ovaries are situated antero-lateral to the developing uterus. The ratio of the length of the uterus to the ovary becomes 1 at 18 weeks of gestation.

\section{Group III (22 - 26 Weeks)}

At this stage, the developing uterus is bigger in size as compared to the previous age group. By $22^{\text {nd }}$ week the length of developing uterus is $12 \mathrm{~mm}$ and the ovaries measure 8.5 $\mathrm{mm}$, thereby giving a ratio of 1.41 . The transverse lengths was found to change significantly from $24^{\text {th }}$ weeks of gestation onwards as compared to the longitudinal length of uterus. At $26^{\text {th }}$ week the length of uterus is $18 \mathrm{~mm}$, ovaries measure $12.8 \mathrm{~mm}$, thereby giving a ratio of 1.41 . The ovaries are present further laterally than the previous age group. The ovaries are observed to be progressively smaller in longitudinal dimension when compared to the uterus in this gestational age group.

\section{Group IV (26 - 30 Weeks)}

The length of developing uterus at $27^{\text {th }}$ week is $16 \mathrm{~mm}$. The ovaries measure $10 \mathrm{~mm}$, thereby giving a ratio of 1.6. By the 29th week, the ovaries are observed to be progressively smaller in longitudinal dimension when compared to the uterus in this gestational age group. The uterus measures $21.3 \mathrm{~mm}$. The ovary measures $14.2 \mathrm{~mm}$ and the ratio of the length of the ovary to the uterus is 1.5 .

\section{Group V (30 - 34 Weeks)}

The developing uterus at $30^{\text {th }}$ week is significantly bigger in size than the previous age group and the length of developing uterus is $22.8 \mathrm{~mm}$. The ovary measures $15.2 \mathrm{~mm}$ and the ratio of the length of the ovary to the uterus is 1.5 . At $34^{\text {th }}$ week the length of uterus is $22.5 \mathrm{~mm}$ and the ovaries measure $12.2 \mathrm{~mm}$, thus giving a ratio of 1.84 . The ovaries are observed to be progressively smaller in longitudinal dimension when compared to the uterus in this gestational age group.

\section{Group VI (34 - 40 Weeks)}

At $40^{\text {th }}$ week, the length of uterus is $36 \mathrm{~mm}$. The ovaries appear smaller as weeks of gestation towards full term approaches and are observed to be smaller in size when 
compared to the uterus in this gestational age group owing to differential growth in dimension between ovaries and developing uterus.

A Pearson correlation coefficient was computed to assess the relationship between the increases in uterine length to that of ovarian length. There was a positive correlation between the two variables, $r=0.915, n=70, p=0.001$. A scatterplot summarises the results (Figure 1). Overall, there was a strong, positive correlation between uterine lengths to that of ovarian length. Increases in uterine length were positively correlated with increases in ovarian length.

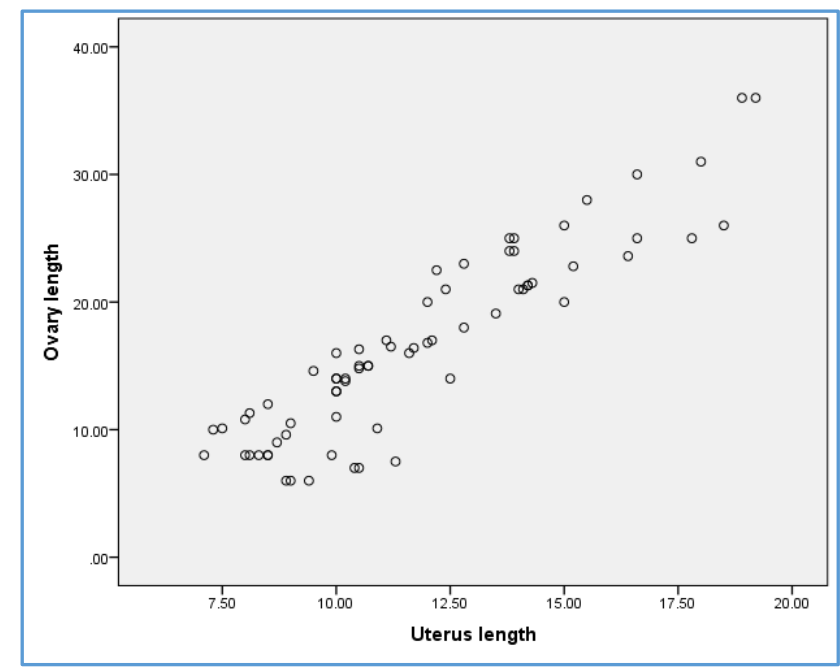

Figure 1. Pearson Correlation Coefficient between Increases in Uterine Length to that of Ovarian Length

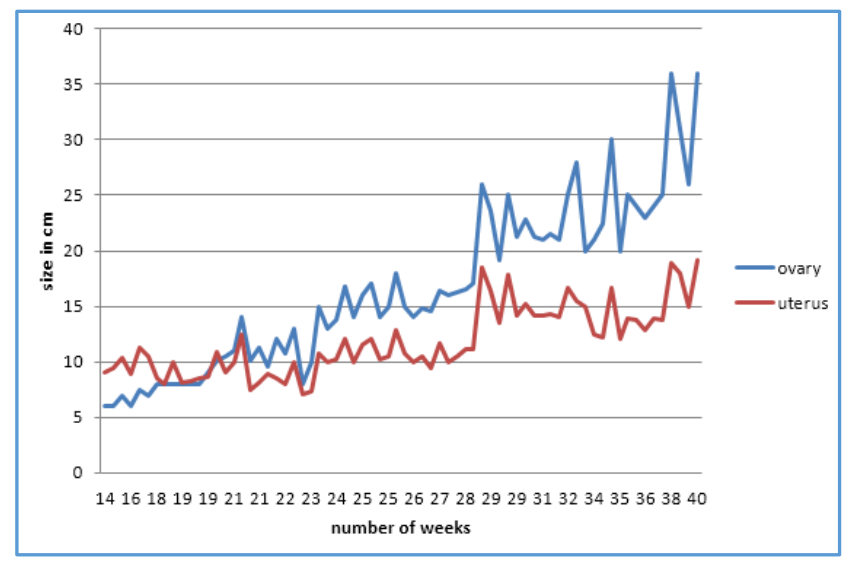

Figure 2. Comparative Growth of Uterus and Ovary in Human Foetuses

\begin{tabular}{|c|c|c|c|c|c|}
\hline Group & $\begin{array}{c}\text { No. of } \\
\text { Cases }\end{array}$ & $\begin{array}{c}\text { Gestational } \\
\text { Age } \\
\text { (In Weeks) }\end{array}$ & $\begin{array}{c}\text { CRL } \\
\text { (In } \\
\text { cm) }\end{array}$ & $\begin{array}{c}\text { Uterus } \\
\text { Length } \\
\text { in mm Mean } \\
\text { (SD) }\end{array}$ & $\begin{array}{c}\text { Ovary } \\
\text { Length } \\
\text { mm Mean } \\
\text { (SD) }\end{array}$ \\
\hline I & 8 & $14-18$ & $10-16$ & $6.93(.86)$ & $9.50(1.13)$ \\
\hline II & 15 & $18-22$ & $17-21$ & $10.23(1.87)$ & $9.13(1.32)$ \\
\hline III & 16 & $22-26$ & $23-25$ & $14.31(2.48)$ & $10.33(1.52)$ \\
\hline IV & 11 & $26-30$ & $26-29$ & $20.00(3.85)$ & $13.65(3.01)$ \\
\hline V & 9 & $30-34$ & $29-32$ & $22.37(2.54)$ & $14.26(1.39)$ \\
\hline VI & 11 & $34-40$ & $33-38$ & $27.27(5.27)$ & $15.26(2.51)$ \\
\hline Table 1. Crown-Rump Length and Mean Growth of Uterus \\
and Ovary in Progressive Weeks of Human Foetuses \\
\hline
\end{tabular}

\section{DISCUSSION}

The fusion of paramesonephric ducts to form the uterus have been highlighted by different researchers; however, the exact time of its fusion during embryogenesis still remain a dispute in the absence of Anti-Mullerian hormones in females. So the paramesonephric duct's fusion to form the fundus, the body, the cervix and upper part of vagina has been universally accepted. However, the process of gradual fusion of caudal part of paramesonephric duct remains a speculation in humans.

According to Sanfilippo JS,12 fusion occurs at 8 weeks of gestation, begins at caudal end and is completed at the fundus. However, Larsen $\mathrm{WJ}^{13}$ concluded that the paramesonephric ducts arise by craniocaudal invagination of a ribbon of thickened coelomic epithelium. In the present study, the earliest available specimen i.e. 14 weeks, there is already V-shaped uterine corpus as a result of fusion as two forms are separated by a depression along its upper border. The unfused part of the paramesonephric ducts signals that the uterine tube is being formed towards the uterine horn. This is one factor to conclude that the fusion is caudocranial.

From 19th weeks, the shape assumes more or less miniature adult uterus shape, i.e. pyriform shape. We find that the transverse lengths were found to change significantly from 24th weeks of gestation onwards as compared to the longitudinal length of uterus. This may be attributed to the differentiation and development of smooth muscle of the uterus markedly at around the $24^{\text {th }}$ week of gestation. Konishi I $^{14}$ concluded that smooth muscle differentiation begins at about 18 weeks and myometrium is formed in the outer layer of the wall by 31 weeks gestation. Sulak 0 et al ${ }^{15}$ did not detect a constancy in the length of ovary, rather it varied between 10 and $18 \mathrm{~mm}$ and found that the widths and the thicknesses of the ovaries increased during 18 - 36 weeks period. Hunter ${ }^{16}$ reported that the length of the ovary was around $15 \mathrm{~mm}$ and stayed almost constant in foetuses between 18 - 36 weeks.

\section{CONCLUSION}

Detailed gross study of the uterus and ovaries in human foetuses was conducted and the observations were noted, critically analysed and discussed with the findings of previous workers in the past. In the earliest specimen i.e. $14^{\text {th }}$ week gestational age, the uterus was visible as longitudinal white mesodermal thickening in the midline of the false pelvis, ovary measures $6 \mathrm{~mm}$ and uterus measures $9 \mathrm{~mm}$, ratio being 0.67 . At $18^{\text {th }}$ week, the dimension is similar at 10 $\mathrm{mm}$ each and the ratio reaches 1 . Thereafter, the ovaries continue to outgrow the uterus and by the $26^{\text {th }}$ week the ovary-uterine ratio reaches 1.4 . This reversal of ratio remains mainly steady till term size. The developing uterus was in close relation with the ovaries and remains so till $36^{\text {th }}$ week of gestation.

\section{REFERENCES}

[1] Speroff L, Fritz M. Clinical gynaecology, endocrinology and infertility. $7^{\text {th }}$ edn. Philadelphia: Lippincott William \& Wilkin 2005.

[2] Woodburne RT, Burkel WE. Essentials of human anatomy. $9^{\text {th }}$ edn. New York: Oxford University 1994. 
[3] Skandalakis JE. The embryology and anatomic basis of modern surgery. 2nd edn. Vol. 2. Greece: Paschalidis Medical Publication 2004.

[4] Gardner B, Gray DJ, Rahilly R. Anatomy - a regional study of human structure. $5^{\text {th }}$ edn. Philadelphia: WB Saunders Company 1986.

[5] Koeppen BM, Stanton BA. Berne \& levy physiology. $6^{\text {th }}$ edn. Philadelphia: Elsevier 2009.

[6] Singer C. A thirteenth century drawing of the anatomy of the uterus and adnexa. Proc R Soc Med 1916;9(Sect Hist Med):43-7.

[7] Hashimoto R. Development of the human mullerian duct in the sexually undifferentiated stage. Anat Rec A Discov Mol Cell Evol Biol 2003;272(2):514-9.

[8] Potemkina DA, Grebanshchikova VI, Korosteleva LI. Interaction of cells of Wolffian duct and mesothelium during initial growth period of mullerian ducts in the axolotl (Ambystomamexicanum). Sov J Dev Biol 1971;2(4):311-22.

[9] Nishimura H. Prenatal versus postnatal malformations based on the Japanese experience on induced abortions in the human being. In: Blandau RJ, edr. Ageing gametes. Basel: Karger 1975: p. 349-68.
[10] Felix W. The development of the urogenital organ. In: Keibel F, Mall FP, eds. Manual of human embryology. Vol. 2. Philadelphia and London: Lippincott 1912: p. 341-60.

[11] Balfour FM, Sedgwick A. On the existence of a rudimentary head-kidney in the embryo chick, and on certain points in the development of the Mullerian duct. Q J Microsc Sci 1879;19:1-20.

[12] Sanfilippo JS. Vulvovaginal and Mullerian anomalies. In: Kliegman RM, Behrman RE, Jenson HB, eds. Nelson Textbook of Paediatrics. 18 ${ }^{\text {th }}$ edn. Philadelphia: Elsevier 2007: p. 2287-9.

[13] Larsen WJ. Human embryology. $3^{\text {rd }}$ edn. Philadelphia: Churchill Livingstone 2001.

[14] Pietryga E, Wozniak W. The growth and topography of the human fetal uterus. Folia Morphol (Warsz) 1992;51(2):165-80.

[15] Sulak O, Malas MA, Esen K, et al. Size and location of the fetal human ovary. Fetal Diagn Ther 2006;21(1):26-33.

[16] Hunter RH. Observations on the development of the human female genital tract. Pub No 414. Contrib Nephrol. Vol. 22. Washington, Carnegie Institute Pg. 91-108. 